\title{
eNOS gene variants and the risk of premature myocardial infarction
}

\author{
Aggeliki-Maria Zigra $^{\mathrm{a}, *}$, Loukianos S. Rallidis $^{\mathrm{b}}$, Georgia Anastasiou $^{\mathrm{a}}$, Efrossyni Merkouri ${ }^{\mathrm{a}}$ and \\ Argyri Gialeraki ${ }^{\mathrm{a}}$ \\ ${ }^{a}$ Laboratory of Haematology and Blood Transfusion Unit, Attikon Hospital, School of Medicine, University of \\ Athens, Athina, Greece \\ ${ }^{\mathrm{b}}$ Second Department of Cardiology, Attikon Hospital, School of Medicine, University of Athens, Athina, Greece
}

\begin{abstract}
.
BACKGROUND: Endothelial nitric oxide synthase (eNOS) as well as nitric oxide play an important role in the regulation of cardiovascular function. There are limited and controversial data regarding the impact of polymorphisms of eNOS gene that is implicated in the vasoconstrictive properties of the endothelium in the pathogenesis of premature myocardial infarction (MI).

OBJECTIVE: We examined whether two common polymorphisms of eNOS gene (G894T and T786C) are associated with the development of premature MI.

METHODS: We recruited 107 patients with premature MI and compared them to 103 age- and sex- matched controls. All patients underwent coronary angiogram and were classified into the subgroup of patients with 'normal' or 'near normal' coronary arteries and the subgroup of patients with significant coronary artery disease $(\geqslant 50 \%$ stenosis in lumen diameter of coronary arteries). The genetic polymorphisms of eNOS gene were assayed with polymerase chain reaction and reverse hybridization. RESULTS: Nineteen patients (17.8\%) had 'normal' or 'near normal' coronary arteries. A significantly higher frequency of homozygosity for the $786 \mathrm{C}(32 \%)$ and the $894 \mathrm{~T}(21 \%)$ alleles of the eNOS gene in patients who develop early MI in the setting of angiographically 'normal' or 'near normal' coronary arteries were found.

CONCLUSIONS: Our data suggest that the T786C and the G894T genetic polymorphisms are associated with the development of $\mathrm{MI}$ in very young individuals, whose coronary arteries are characterized by very small atheromatic burden.
\end{abstract}

Keywords: Cardiovascular disease, genetic polymorphisms, early myocardial infarction, endothelial nitric oxide synthase

\section{Introduction}

It is well established that endothelial function is critical for vascular homeostasis. This is mediated via production of a number of biochemical mediators with vasodilatory or vasoconstrictive properties $[4,11,18]$. Endothelial - derived nitric oxide (eNO) produced by endothelial nitric oxide synthase (eNOS) plays a pivotal role in the preservation of the endothelium homeostasis, regulation of vascular tone and endothelialleukocyte interaction $[3,26]$.

\footnotetext{
* Corresponding author: Aggeliki-Maria Zigra, Laboratory of Haematology and Blood Transfusion Unit, Attikon Hospital, School of Medicine, University of Athens, Athina, Greece. E-mail: zou2zigra@yahoo.gr.
}

The gene encoding eNOS is located on chromosome 7 (7q35-36) [7,13]. Several polymorphisms of the eNOS gene have been reported so far but their impact on eNO production and expression is not yet clarified. The genetic polymorphisms G894T and T786C are the most clinically relevant polymorphisms in the eNOS gene that have been described $[2,13]$. However, the G894T(Glu298Asp) and T786C (a mutation located in the 5-flanking region of the eNOS gene) genetic polymorphisms seem to be implicated in the development of coronary heart disease (CHD) [8,9,14, $17,25]$. Previous studies have shown that these polymorphisms are associated with reduced eNO generation $[7,9,13]$. Furthermore, they may be implicated in the development of premature myocardial infarction 
(MI), although their actual role has been questioned by several studies $[1,2,6,15,19,25]$.

Young adults constitute a relatively small percentage of patients who sustain MI. It is estimated that young patients make up between $5 \%$ and $10 \%$ of all MIs $[10,16,21,23]$. Young patients with MI share a different risk factor profile compared to older patients. In particular, MI at young ages is usually associated with less atheromatic burden in coronary arteries and higher prevalence of smoking and family history of CHD [22, 24]. Another distinct characteristic of patients with MI at young age is the relatively high proportion of angiographically 'normal' or 'near normal' coronary arteries [28]. This suggests that the impact of other pathogenetic mechanisms such as coronary spasm may have more pronounced role in the development of premature MI [10,22].

In the present study, we studied the prevalence of the G894T and $T 786 C$ genetic polymorphisms in young survivors ( $\leqslant 35$ years) of MI in order to estimate their impact on the development of premature MI.

\section{Materials and methods}

The study population consisted of 107 patients who had survived their first MI occurring $\leqslant 35$ years of age. They had been admitted to the Coronary Care Unit of the General Hospital of Nikea and the University General Hospital Attikon between January 2003 and December 2010. The diagnosis of MI was based on the presence of $\geqslant 2$ of the following three criteria: (1) characteristic chest pain lasting $>30 \mathrm{~min}$, (2) ST elevation $>0.1 \mathrm{mV}$ on at least 2 adjacent electrocardiographic leads and (3) increase of creatine kinase (CK) to peak levels of at least 2-fold the upper limit of normal values [20].

We also recruited 103 healthy age- and sex-matched subjects who had undergone a minor orthopedic intervention in the University General Hospital Attikon who served as the control group. All control subjects had no personal or family history of cardiovascular disease. The study was approved by the ethics committee of our institution and all subjects gave their informed consent.

All participants were interviewed and special attention was paid on reporting cardiovascular risk factors and use of medication. The following definitions were used: hypertension, blood pressure $\geqslant$ 140/90 $\mathrm{mmHg}$ and/or antihypertensive treatment; hypercholesterolemia, total cholesterol $>200 \mathrm{mg} / \mathrm{dl}$ and/or lipid lowering medication. Smokers from the patients group were considered those who smoked until MI and from the controls those who reported smoking currently and regularly (at least five cigarettes per day).

\subsection{Coronary angiography}

All patients underwent coronary angiography and left venticulography by the Judkins technique. According to angiographic findings they were divided into two subgroups. The first subgroup consisted of patients in whom epicardial coronary arteries had smooth contours and no focal diameter reduction ('normal') or coronary arteries with non-haemodynamically significant atherosclerotic lesions ( $<50 \%$ stenosis) ("near normal'). The second subgroup was angiographically defined as $\geqslant 50 \%$ stenosis in lumen diameter of coronary arteries (significant CHD).

\subsection{Blood sampling and biochemical analysis}

Peripheral blood samples were collected from patients and controls after overnight fasting for assessing levels of lipids and genotyping. In particular, blood from patients was collected within $24 \mathrm{~h}$ from admission.

Total cholesterol, triglycerides as well as High Density Lipoprotein (HDL) cholesterol levels were determined using enzymatic colorimetric assays (Schiapparelli Biosystems Inc., USA). Low Density Lipoprotein (LDL) cholesterol was calculated by the Friedewald equation [12].

\subsection{DNA analysis}

Genomic DNA was extracted from EDTA anticoagulated blood by using standard methods (CVD strip assay A, Viennalab, Austria). The presence of genetic polymorphisms of the eNOS gene ( $G 894 T$ and T786C polymorphisms), was assayed by polymerase chain reaction (PCR) and amplification of the target sequence using biotinylated primers (T786C polymorphism: 5' CACCTGCATTCTGGGAACTGTA 3' \& $5^{\prime}$ GCCGCAGTAGCAGAGAGAC 3'; G894T polymorphism: $5^{\prime}$ GGCACCTCAAGGACCAGCT $3^{\prime} \& 5^{\prime} A C G$ GCTGGACCCCAGG $3^{\prime}$ ). The PCR cycles were optimized as follows: 2 min of initial denaturation at $94^{\circ} \mathrm{C}$, followed by 35 cycles of amplification (15 sec denaturation at $94^{\circ} \mathrm{C}, 30 \mathrm{sec}$ annealing at $58^{\circ} \mathrm{C}, 30 \mathrm{sec}$ extension at $72^{\circ} \mathrm{C}$ ) and final extension of $3 \mathrm{~min}$ at $72^{\circ} \mathrm{C}$. 
Table 1

Prevalence of traditional risk factors in young survivors of myocardial infarction

\begin{tabular}{|c|c|c|c|c|c|c|c|c|}
\hline & \multirow[b]{2}{*}{ Total } & \multicolumn{2}{|c|}{ Patients $(n=107)$} & \multirow[b]{2}{*}{$\begin{array}{l}\text { Controls } \\
(n=103)\end{array}$} & \multicolumn{4}{|c|}{$p$} \\
\hline & & $\begin{array}{c}\text { Significant } \\
\text { CHD }(n=88)\end{array}$ & $\begin{array}{l}\text { 'Normal' or 'near } \\
\text { normal' }(n=19)\end{array}$ & & $P^{\#}$ & $P^{*}$ & $P^{\dagger}$ & $P^{\ddagger}$ \\
\hline Age (year) & $32.1 \pm 3.1$ & $32.5 \pm 3.4$ & $31.4 \pm 2.3$ & $31.8 \pm 3.2$ & & & & \\
\hline Current smokers (\%) & 95.2 & 96.3 & 94.1 & 47.6 & $<0.001$ & $<0.001$ & $<0.001$ & NS \\
\hline Hypertension (\%) & 9.8 & 12.6 & 5.0 & 1.9 & $<0.001$ & $<0.001$ & 0.025 & $<0.001$ \\
\hline Total cholesterol (mg/dl) & $238.2 \pm 71$ & $251.8 \pm 68$ & $224.8 \pm 50$ & $189.6 \pm 24$ & $<0.001$ & $<0.001$ & 0.01 & NS \\
\hline Triglycerides (mg/dl) & $170.9 \pm 90$ & $165.2 \pm 86$ & $175.6 \pm 125$ & $107 \pm 63$ & $<0.001$ & $<0.001$ & $<0.001$ & NS \\
\hline LDL cholesterol (mg/dl) & $156.1 \pm 58$ & $174.6 \pm 70$ & $130.6 \pm 45$ & $119.4 \pm 27$ & $<0.001$ & $<0.001$ & NS & $<0.001$ \\
\hline HDL cholesterol (mg/dl) & $33.5 \pm 11.7$ & $32.6 \pm 11.6$ & $34.3 \pm 14$ & $50 \pm 8.5$ & 0.02 & 0.015 & 0.025 & NS \\
\hline
\end{tabular}

\# $P$ patients vs. controls; ${ }^{*} P$ patients with significant $\mathrm{CHD}$ vs. controls; ${ }^{\dagger} P$ patients with 'normal' or 'near normal' coronary arteries vs. controls;

$\ddagger P$ patients with significant CHD vs. patients with 'normal' or near 'normal' coronary arteries; NS Not Significant; \pm SD.

The amplification products were hybridized to a test strip containing allele-specific oligonucleotide probes (T786C polymorphism wild type: $5^{\prime}$ CAAGCTCTTCCCTGGCAG 3' \& mutant: $5^{\prime}$ CAAGCTCTTCCCTG$G C G G 3^{\prime}$; G894T polymorphism wild type: $5^{\prime} T G G G$ GGCTCATCTGGGGC $3^{\prime}$ \& mutant: $5^{\prime}$ TGGGGGATCATCTGGGGC $3^{\prime}$ ) immobilized as an array of parallel lines. Bound biotinylated sequences were detected using streptavidin-alkaline phosphatase and specific color substrate (CVD strip assay A, Viennalab, Austria).

\subsection{Statistical analysis}

Quantitative values are expressed as median (S.D.) and were compared using unpaired Student's t-test. For repeated measurements comparisons between groups were initially tested with Freedman analysis of variance. Discontinuous variables were tested by a contingency $\chi^{2}$ test. A $p$ value $<0.05$ was considered significant. The SPSS version 13 (SPSS Inc., Chicago, USA) statistical package was used.

\section{Results}

\subsection{Traditional risk factors}

CK peak levels during the acute phase of MI were $2455 \pm 2240 \mathrm{U} / \mathrm{ml}$. The prevalence of traditional risk factors for MI and biochemical measurements are shown in Table 1. There was a significantly higher prevalence of smoking and hypertension in patients than in controls. Total cholesterol, triglycerides and LDL cholesterol levels were also significantly higher, while HDL cholesterol levels were significantly lower in patients compared to controls.
Patients with MI were further divided into two subgroups according to coronary anatomy ('normal' or 'near normal' coronary arteries and significant CHD) as shown in Table 1. The frequency of smoking and hypertension as well as the levels of total cholesterol and triglycerides remained significantly higher in both subgroups compared to controls. LDL cholesterol levels remained significantly higher only in the patients with MI significant CHD compared to controls, while HDL cholesterol levels were significantly lower in both subgroups compared to controls.

\section{2. eNOS polymorphisms}

\subsubsection{T786C polymorphism}

The prevalence of homozygocity for the $C$ allele was significantly higher in patients compared to controls $(16 \%$ vs. $6 \%, p<0.001)$ (Table 2$)$. There was a higher, although not statistically significant, prevalence of $C C$ homozygocity in patients with MI and significant CHD than in control subjects ( $12 \%$ vs. $6 \%, p=$ 0.06 ), as well as the prevalence of $C C$ homozygocity was significantly higher in patients with 'normal' or 'near normal' coronary arteries compared to controls (32\% vs. $6 \%, p<0.001$ ) (Table 2 ).

\subsubsection{G894T polymorphism}

The prevalence of homozygocity for the $T$ allele was significantly higher only in patients with 'normal' or 'near normal' coronary arteries compared to controls ( $21 \%$ vs. $10 \%, p<0.001$ ) (Table 3 ).

\section{Discussion}

It is well established that the majority of patients who develop MI show significantly higher values of at least one of the traditional risk factors (smoking, hy- 
Table 2

Prevalence of T786C polymorphism in patients and control subjects

\begin{tabular}{|c|c|c|c|c|c|c|c|c|c|}
\hline & \multirow[b]{2}{*}{$\begin{array}{c}\text { T786C } \\
\text { polymorphism }\end{array}$} & \multirow[b]{2}{*}{ Total } & \multicolumn{2}{|c|}{ Patients $(n=107)$} & \multirow[b]{2}{*}{$\begin{array}{l}\text { Controls } \\
(n=103)\end{array}$} & \multicolumn{4}{|c|}{$p$} \\
\hline & & & $\begin{array}{c}\text { Significant } \\
\text { CHD }(n=88)\end{array}$ & $\begin{array}{l}\text { 'Normal' or 'near } \\
\text { normal' }(n=19)\end{array}$ & & $P^{\#}$ & $P^{*}$ & $P^{\dagger}$ & $P^{\ddagger}$ \\
\hline & $\mathrm{TT}$ & $41(38 \%)$ & $35(40 \%)$ & $6(32 \%)$ & $70(68 \%)$ & $<0.001$ & $<0.001$ & $<0.001$ & NS \\
\hline & $\mathrm{TC}$ & $49(46 \%)$ & $42(48 \%)$ & $7(36 \%)$ & $27(26 \%)$ & $<0.001$ & $<0.001$ & NS & NS \\
\hline & $\mathrm{CC}$ & $17(16 \%)$ & $11(12 \%)$ & $6(32 \%)$ & $6(6 \%)$ & $<0.001$ & NS & $<0.001$ & $<0.001$ \\
\hline Allele & $\mathrm{T}$ & $131(61 \%)$ & $112(64 \%)$ & $19(50 \%)$ & $167(81 \%)$ & 0.03 & NS & $<0.001$ & 0.04 \\
\hline frequency & $\mathrm{C}$ & $83(39 \%)$ & $64(36 \%)$ & $19(50 \%)$ & $39(19 \%)$ & $<0.001$ & $<0.001$ & $<0.001$ & 0.04 \\
\hline
\end{tabular}

$\#^{*} P$ patients vs. controls; ${ }^{*} P$ patients with significant $\mathrm{CHD}$ vs. controls; ${ }^{\dagger} P$ patients with 'normal' or near 'normal' coronary arteries vs. controls;

$\ddagger P$ patients with significant CHD vs. patients with 'normal' or 'near normal' coronary arteries; NS Not Significant.

Table 3

Prevalence of G894T polymorphism in patients and control subjects

\begin{tabular}{|c|c|c|c|c|c|c|c|c|c|}
\hline & \multirow[b]{2}{*}{$\begin{array}{c}\text { G894T } \\
\text { polymorphism }\end{array}$} & \multirow[b]{2}{*}{ Total } & \multicolumn{2}{|c|}{ Patients $(n=107)$} & \multirow[b]{2}{*}{$\begin{array}{l}\text { Controls } \\
(n=103)\end{array}$} & \multicolumn{4}{|c|}{$p$} \\
\hline & & & $\begin{array}{c}\text { Significant } \\
\mathrm{CHD}(n=88)\end{array}$ & $\begin{array}{l}\text { 'Normal' or 'near } \\
\text { normal' }(n=19)\end{array}$ & & $P^{\#}$ & $P^{*}$ & $P^{\dagger}$ & $P^{\ddagger}$ \\
\hline & GG & $50(47 \%)$ & $43(49 \%)$ & $7(37 \%)$ & $50(49 \%)$ & NS & NS & NS & NS \\
\hline & GT & $46(43 \%)$ & $38(43 \%)$ & $8(42 \%)$ & $42(41 \%)$ & NS & NS & NS & NS \\
\hline & TT & $11(10 \%)$ & $7(8 \%)$ & $4(21 \%)$ & $11(10 \%)$ & NS & NS & $<0.001$ & 0.02 \\
\hline Allele & $\mathrm{G}$ & $146(68 \%)$ & $124(70 \%)$ & $22(58 \%)$ & $142(69 \%)$ & NS & NS & NS & NS \\
\hline frequency & $\mathrm{T}$ & $68(32 \%)$ & $52(30 \%)$ & $16(42 \%)$ & $64(31 \%)$ & NS & NS & 0.04 & NS \\
\hline
\end{tabular}

\# $P$ patients vs. controls; ${ }^{*} P$ patients with significant $\mathrm{CHD}$ vs. controls; ${ }^{\dagger} P$ patients with 'normal' or 'near normal' coronary arteries vs. controls;

${ }^{\ddagger} P$ patients with significant CHD vs. patients with 'normal' or 'near normal' coronary arteries; NS Not Significant.

pertension, hyperlipidaemia) associated to atherosclerosis. However, almost $20 \%$ of very young patients with MI appear with 'normal' or 'near normal' arteries. In our study, we investigated the hypothesis that genetic factors that affect pathways such as endothelial function and coronary artery spasm might trigger the development of MI in young patients who have no or minor atheromatic burden as proved by angiographic data. We evaluated the frequency of two common polymorphisms of the eNOS gene (G894T, T786C) associated with reduced production of eNO and ineffective vasodilation in a group of very young patients with MI and we further divided this group in two subgroups according to angiographic data of the patients. We found that patients who develop premature MI in the setting of angiographically 'normal' or 'near normal' coronary arteries present with higher frequency of homozygosity for the $T 786 C$ and the $G 894 T$ genetic polymorphisms of the eNOS gene.

Previous studies have reported conflicting results regarding the association of the genetic polymorphisms of the eNOS gene with the risk of MI. Nakayama et al. reported that the frequency of the $T 786 C$ polymorphism was significantly higher in MI patients with no stenosed vessels compared to those with stenosed vessels and concluded that this polymorphism is associated with the development of MI in patients without significant CHD [19]. Granath et al. found no signifi- cant difference between patients and controls regarding frequency of $C C$ (mutant) genotype [15]. Additionally, Ciftçi et al. showed that the high frequency of $T T$ (wild type) genotype in the patients may support no relationship of $7786 C$ polymorphism with premature MI [6].

Similar conflicting results concerning the development of premature MI were obtained for the G894T genetic polymorphism. Spence et al. observed that individuals, who were homozygous for the mutant allele (TT genotype), were not associated with an increased risk of MI [25]. Antoniades et al. in an elegantly designed study with 229 patients with premature MI demonstrated that homozygosity for G894T polymorphism is associated with a significantly increased risk for premature MI [2]. Andrikopoulos et al. reported that the frequency of the G894T polymorphism was found to be significantly higher in MI patients [1]. Similarly, Isordia-Salas et al. showed that the Glu298Asp polymorphism represents an independent risk factor for premature MI [17].

The unique feature of our study was the recruitment of patients who suffered MI very early in their life ( $\leqslant$ 35 years). By lowering the age limit we formed a subgroup of young patients with specific characteristics. The atheromatic burden in coronary arteries in this age group is relatively low as this is reflected by the relatively high prevalence of 'normal' or 'near normal' coronary angiograms. In our young population $17.8 \%$ 
of the patients had angiographically 'normal' or 'near normal' coronary arteries. By comparison, this prevalence is $<5 \%$ in older population [28]. Moreover, in young age the presence of other traditional cardiovascular risk factors is uncommon with the exception of smoking and hyperlipidemia.

The precise mechanism of development of premature MI is unknown. The low atheromatic burden of coronary arteries in the first four decades of life allows us to hypothesize that mechanisms such as hypercoagulable state, coronary artery spasm and inflammation per se or in combination may play a role in the pathogenesis of premature MI. Uncompromised production of eNO leading to ineffective vasodilation and thus increased possibility of spasm might constitute a candidate pathogenetic mechanism for the development of MI in this group of patients. Therefore, the study of polymorphisms in the eNOS gene associated with reduced eNO production might be of interest in this group of patients. Implication of polymorphisms involved either in the regulation of expression (T786C) or in post-translational modification of eNOS (G894T) was therefore investigated in a group of very young patients with MI.

In particular, homozygosity for $T 786 C$ polymorphism has been reported to produce a significant reduction in the eNOS gene promoter activity and thus eNO production [13]. Moreover, it has been suggested that homozygosity for $G 894 T$ polymorphism leads to susceptibility to proteolytic cleavage in endothelial cells and vascular tissues and results in reduced levels of functional eNOS and subsequently reduced levels of eNO [9].

Few limitations of our study have to be addressed. The results may be biased since we recruited only survivors of MI. As a result, patients who died before arriving at hospital might have had a different pattern of the above studied polymorphisms. Another limitation is the relatively small size, for a genetic study, of our population.

In conclusion, our study shows that the $T 786 C$ and the $G 894 T$ genetic polymorphisms seem to be associated with the development of MI in very young individuals whose coronary arteries are characterized by very small atheromatic burden. However, large studies need to be undertaken in young populations in order to further elucidate the gene-environment interrelation that underlies the pathophysiology of premature MI.

\section{References}

[1] GK Andrikopoulos, DK Grammatopoulos, SE Tzeis, SI Zervou, DJ Richter, MN Zairis, EJ Gialafos, DC Sakellariou,
SG Foussas, AS Manolis, CI Stefanadis, PK Toutouzas, EW Hillhouse, GEMIG study investigators, Association of the $894 \mathrm{G}>\mathrm{T}$ polymorphism in the endothelial nitric oxide synthase gene with risk of acute myocardial infarction, BMC Med Genet 9 (2008), 43-49.

[2] C Antoniades, D Tousoulis, C Vasiliadou, C Pitsavos, C Chrysochoou, D Panagiotakos, C Tentolouris, K Marinou, N Koumallos, C Stefanadis, Genetic polymorphism on endothelial nitric oxide synthase affects endothelial activation and inflammatory response during the acute phase of myocardial infarction, J Am Coll Cardiol 46 (2005), 1101-9.

[3] DN Atochin, PL Huang, Endothelial nitric oxide synthase transgenic models of endothelial dysfunction, Pflugers Arch 460 (2010), 965-74.

[4] D Behrendt, P Ganz, Endothelial function. From vascular biology to clinical applications, Am J Cardiol 90 (2002), 40L48L.

[5] K Bian, MF Doursout, F Murad, Vascular system: role of nitric oxide in cardiovascular diseases, J Clin Hypertens (Greenwich) 10 (2008), 304-10.

[6] C Ciftçi, S Melil, Y Cebi, M Ersöz, P Cağatay, M Kiliçgedik, BS Duman, Association of endothelial nitric oxide synthase promoter region (T-786C) gene polymorphism with acute coronary syndrome and coronary heart disease, Lipids Health Dis 7 (2008), 5.

[7] D Colomba, G Duro, S Corrao, C Argano, T Chiara, D Nuzzo, F Pizzo, G Parrinello, R Scaglione, G Licata, Endothelial nitric oxide synthase gene polymorphisms and cardiovascular damage in hypertensive subjects: an Italian case-control study, Immun Ageing 5 (2008), 4.

[8] MG Colombo, U Paradossi, MG Andreassi, N Botto, S Manfredi, S Masetti, A Biagini, A Clerico, Endothelial nitric oxide synthase gene polymorphisms and risk of coronary artery disease, Clin Chem 49 (2003), 389-95.

[9] RG Dias, MM Gowdak, AC Pereira, Genetics and cardiovascular system: influence of human genetic variants on vascular function, Genes Nutr 6 (2011), 55-62.

[10] M Doughty, R Mehta, D Bruckman, Acute myocardial infarction in the young: the university of michigan experience, $A m$ Heart $J 143$ (2002), 56-62.

[11] CT Esmon, NL Esmon, The link between vascular features and thrombosis, Annu Rev Physiol 73 (2011), 503-14.

[12] WT Friedewald, RI Levy, DS Fredrickson, Estimation of the concentration of low-density lipoprotein cholesterol in plasma, without use of the preparative ultracentrifuge, Clin Chem 18 (1972), 499-502.

[13] G Ghilardi, ML Biondi, M DeMonti, M Bernini, O Turri, F Massaro, E Guagnellini, R Scorza, Independent risk factor for moderate to severe internal carotid artery stenosis: T786C mutation of the endothelial nitric oxide synthase gene, Clin Chem 48 (2002), 989-93.

[14] A Gluba, M Banach, J Rysz, G Piotrowski, W Fendler, T Pietrucha, Is polymorphism within eNOS gene associated with the late onset of myocardial infarction? A pilot study, Angiology 60 (2009), 588-95.

[15] B Granath, RR Taylor, FM van Bockxmeer, CD Mamotte, Lack of evidence for association between endothelial nitric oxide synthase gene polymorphisms and coronary artery disease in the Australian Caucasian population, J Cardiovasc Risk 8 (2001), 235-41.

[16] I Isordia-Salas, AL Mendoza-Valdez, E Almeida-Gutiérrez, G Borrayo-Sánchez, Genetic factors of the hemostatic system in young patients with myocardial infarction, Cir Cir 78 (2010), $93-7$. 
[17] I Isordia-Salas, A Leaños-Miranda, G Borrayo-Sánchez, The Glu298ASP polymorphism of the endothelial nitric oxide synthase gene is associated with premature ST elevation myocardial infarction in Mexican population, Clin Chim Acta 411 (2010), 553-7.

[18] C Michiels, Endothelial cell functions, J Cell Physiol 196 (2003), 430-43.

[19] M Nakayama, H Yasue, M Yoshimura, Y Shimasaki, H Ogawa, K Kugiyama, Y Mizuno, E Harada, S Nakamura, T Ito, Y Saito, Y Miyamoto, Y Ogawa, K Nakao, T-786->C mutation in the $5^{\prime}$-flanking region of the endothelial nitric oxide synthase gene is associated with myocardial infarction, especially without coronary organic stenosis, Am J Cardiol 86 (2000), 628-634.

[20] Nomenclature and criteria for diagnosis of ischemic heart disease. Report of the Joint International Society and Federation of Cardiology/World Health Organization task force on standardization of clinical nomenclature, Circulation 59 (1979), 607-609.

[21] PT O'Gara, FG Kushner, DD Ascheim, DE Jr Casey, MK Chung, JA de Lemos, SM Ettinger, JC Fang, FM Fesmire, BA Franklin, CB Granger, HM Krumholz, JA Linderbaum, DA Morrow, LK Newby, JP Ornato, N Ou, MJ Radford, JE Tamis-Holland, CL Tommaso, CM Tracy, YJ Woo, DX Zhao, ACCF/AHA Guideline for the Management of ST-Elevation Myocardial Infarction: A Report of the American College of Cardiology Foundation/American Heart Association Task Force on Practice Guidelines, Circulation 127 (2013), e362425 .
[22] DB Panagiotakos, LS Rallidis, C Pitsavos, C Stefanadis, D Kremastinos, Cigarette smoking and myocardial infarction in young men and women: a case-control study, Int J Cardiol 116 (2007), 371-5.

[23] LS Rallidis, A Gialeraki, C Komporozos, P Vavoulis, G Pavlakis, A Travlou, I Lekakis, DT Kremastinos, Role of methylenetetrahydrofolate reductase $677 \mathrm{C}->\mathrm{T}$ polymorphism in the development of premature myocardial infarction, Atherosclerosis 200 (2008), 115-20.

[24] LS Rallidis, A Gialeraki, E Merkouri, G Liakos, N Dagres, D Sionis, A Travlou, J Lekakis, DT Kremastinos, Reduced carriership of $4 \mathrm{G}$ allele of plasminogen activator inhibitor-1 $4 \mathrm{G} / 5 \mathrm{G}$ polymorphism in very young survivors of myocardial infarction, J Thromb Thrombolysis 29 (2010), 497-502.

[25] MS Spence, PG McGlinchey, CC Patterson, AR Allen, G Murphy, U Bayraktutan, DG Fogarty, AE Evans, PP McKeown, Endothelial nitric oxide synthase gene polymorphism and ischemic heart disease, Am Heart J 148 (2004), 847-51.

[26] DJ Stuehr, Enzymes of the L-arginine to nitric oxide pathway, J Nutr 134 (2004), 2748S-2751S.

[27] M Takaoka, NOS gene polymorphism, Nihon Rinsho 62 (2004), 103-9.

[28] FH Zimmerman, A Cameron, LD Fisher, Myocardial infarction in young adults: angiographic characterization, risk factors and prognosis (Coronary Artery Surgery Study Registry), J Am Coll Cardiol 26 (1995), 654-61. 


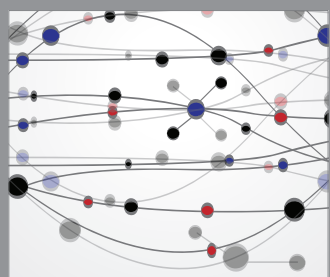

The Scientific World Journal
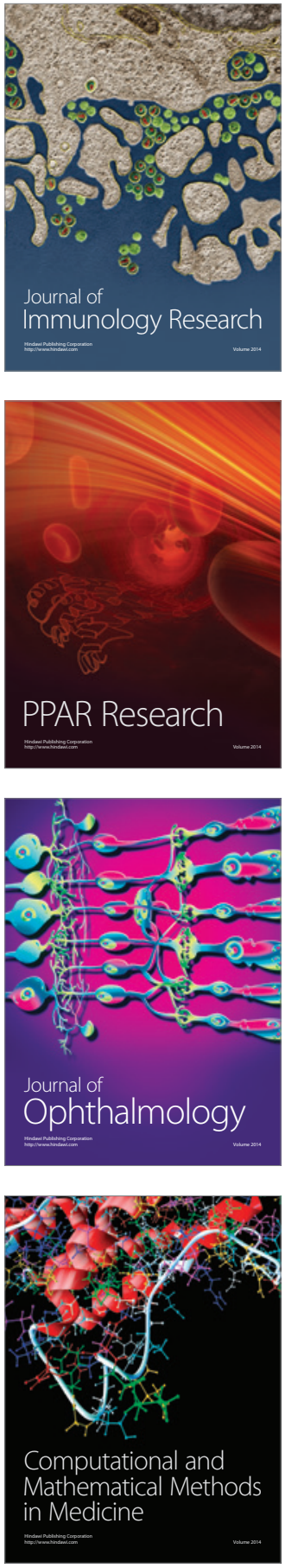

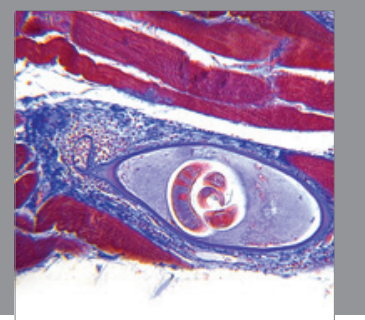

Gastroenterology

Research and Practice
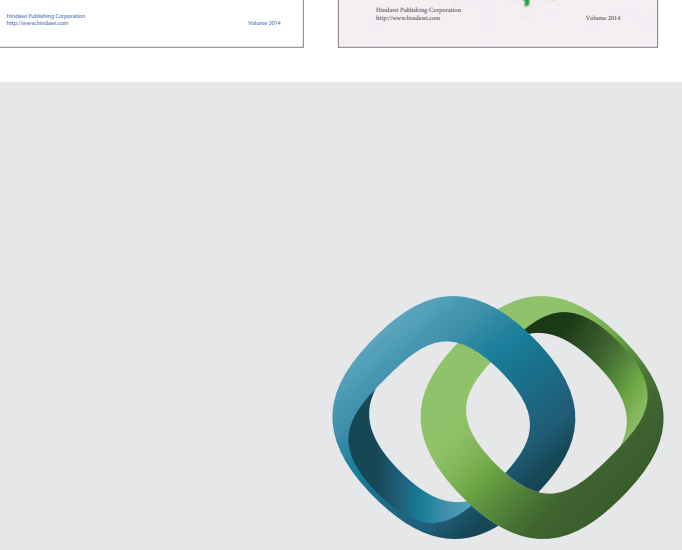

\section{Hindawi}

Submit your manuscripts at

http://www.hindawi.com
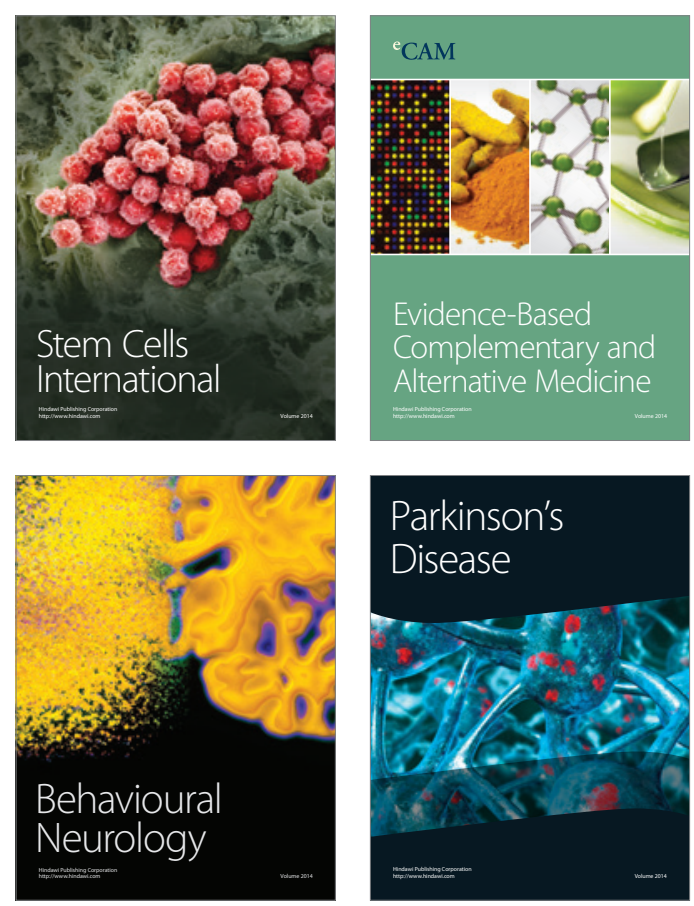

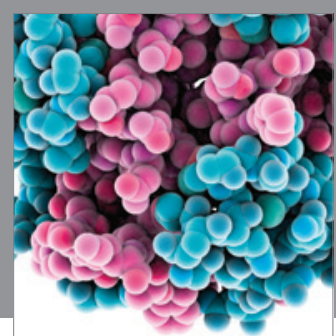

Journal of
Diabetes Research

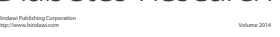

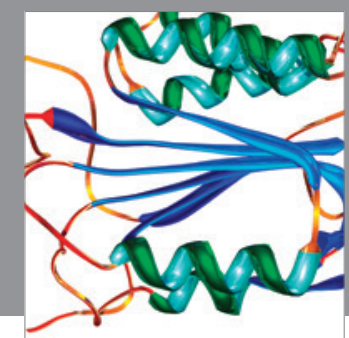

Disease Markers
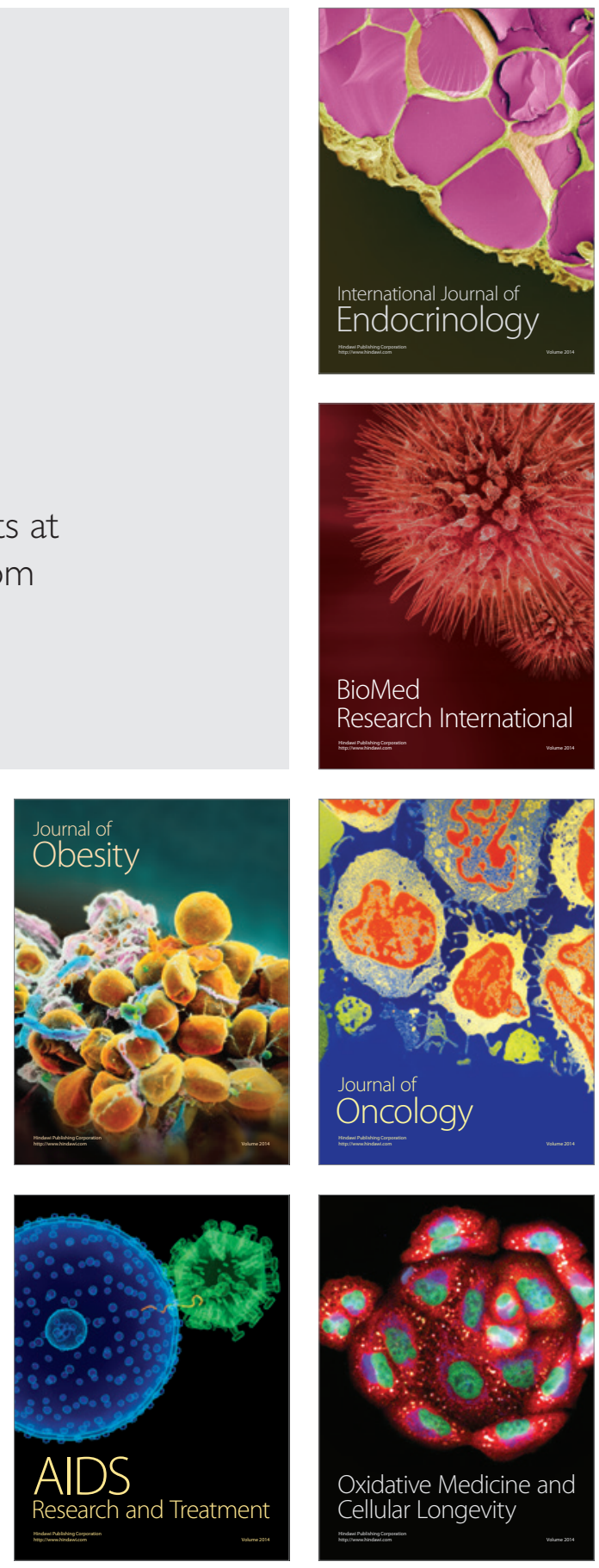